28 Email: pierre.vassiliadis@uclouvain.be

29 Web: http://www.coactionslab.com

9

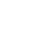

(1)

1

12

3

15

6

7

9

\section{* CORRESPONDENCE TO:}

1 Pierre Vassiliadis

22 Institute of Neuroscience

23 Université catholique de Louvain

24 53, Avenue Mounier

COSY-B1.53.04

6 B-1200 BRUSSELS

27 Belgium

\title{
Motor training strengthens corticospinal suppression during movement preparation
}

\author{
${ }^{1}$ Institute of Neuroscience, Université Catholique de Louvain, 1200, Brussels, Belgium. \\ ${ }^{2}$ Center for Neuroprosthetics (CNP) and Brain Mind Institute (BMI), Swiss Federal Institute of \\ Technology (EPFL), 1202, Geneva, Switzerland
}

\author{
Pierre Vassiliadis $^{1,2 *}$, Gerard Derosiere ${ }^{1}$, Julien Grandjean ${ }^{1}$, Julie Duque $^{1}$
}

8 Abbreviated title: Training strengthens preparatory suppression

Web: http.//www.coactionslab.com 


\section{Abstract}

Training can improve motor skills and modify neural activity at rest and during movement execution. Learning-related modulations may also concern motor preparation but the neural correlates and the potential behavioral relevance of such adjustments remain unclear. In humans, preparatory processes have been largely investigated using transcranial magnetic stimulation (TMS) with several studies reporting decreased corticospinal excitability (CSE) relative to a baseline measure; a phenomenon called preparatory suppression. Here, we investigated the effect of motor training on preparatory suppression of CSE in humans, as compared to modulatory changes at rest. We trained participants to initiate quick movements in an instructed-delay reaction time (RT) task and used TMS to investigate changes in CSE over the practice blocks. Training on the task speeded up RTs, with no repercussion on error rates. Training also increased baseline CSE at rest. Most interestingly, we found that motor activity during action preparation did not mirror the training-related rise in resting CSE. Rather, the degree of preparatory suppression from the rising baseline strengthened with practice. This training-related change in preparatory suppression predicted RT gains (but not the changes in baseline CSE): subjects showing a stronger expansion of preparatory suppression were also those exhibiting larger gains in RTs. Finally, such relationship between RTs and preparatory suppression was also evident at the single-trial level: RTs were generally faster in trials where preparatory suppression was deeper. These findings suggest that training induces changes in motor preparatory processes that are linked to an enhanced ability to initiate fast movements.

New and Noteworthy

Any movement is preceded by a period of preparation, which involves a broad suppression of the corticospinal pathway, a phenomenon called preparatory suppression. Here, we show that motor training strengthens preparatory suppression and that this strengthening is associated with an acceleration of movement initiation. Our findings yield an extension of former work, highlighting a key role of preparatory suppression in training-driven behavioral improvements. 
bioRxiv preprint doi: https://doi.org/10.1101/2020.02.14.948877; this version posted June 20, 2020. The copyright holder for this preprint (which was not certified by peer review) is the author/funder, who has granted bioRxiv a license to display the preprint in perpetuity. It is made available under aCC-BY-NC-ND 4.0 International license.

57 Keywords: motor training; action preparation; transcranial magnetic stimulation; motor-evoked

58 potentials; primary motor cortex; corticospinal excitability; corticospinal suppression, reaction

59 time. 


\section{Introduction}

61

Motor training improves the speed and/or accuracy at which movements are selected, initiated and executed. Significant research has been devoted to unveiling the functional changes at the basis of such improvements (Krakauer et al. 2019). At the neural level, neuroimaging (e.g., Wiestler \& Diedrichsen, 2013; Wenger et al., 2017; Yokoi \& Diedrichsen, 2019) and transcranial magnetic stimulation (TMS) studies (e.g., Rosenkranz et al., 2007; Reis et al., 2008; Mawase et al., 2017) have shown that training is accompanied by a plastic reorganization of the motor system, supporting the formation of new motor memories. Specifically, training amplifies resting motor activity (e.g., Pascual-Leone et al., 1995; Butefisch et al., 2000; Duque et al., 2008; Galea \& Celnik, 2009; Christiansen et al., 2018) and induces learning-specific changes of motor activity during movement execution (Krakauer et al. 2004; Shmuelof et al. 2014; Steele and Penhune 2010). Animal studies also show learning-related modulations of motor activity during action preparation (Makino et al. 2017; Paz et al. 2003; Vyas et al. 2018, 2020) that could reflect an optimization of preparatory processes with training (Mawase et al. 2018). Yet, the behavioral relevance of the effects of training on action preparation remain unclear.

In humans, the excitability of the motor system can be assessed by applying TMS over primary motor cortex (M1), eliciting motor-evoked potentials (MEPs), whose amplitude reflects the excitability of the corticospinal pathway (Derosiere et al. 2020; Derosiere and Duque 2020). When applied during reaction time (RT) tasks, TMS elicits MEPs that are used to assess corticospinal excitability (CSE) changes associated with action preparation and initiation. CSE is often suppressed during action preparation when compared to a baseline, measured at rest. The function of this preparatory suppression (or inhibition) remains unclear (e.g., Greenhouse et al., 2015; Duque et al., 2017; Derosiere, 2018; Hannah et al., 2018). A prominent view is that it assists action selection processes, by preventing the release of premature or incorrect responses (Duque et al. 2010; Quoilin et al. 2018). Indeed, the amount of preparatory suppression was shown to scale with the complexity of selection processes (Duque et al. 2016; Klein et al. 2014). Another hypothesis is that preparatory suppression eases action initiation (Greenhouse et al. 2015; Hasegawa et al. 2017). In this line, a study showed a dependence of RTs on the amount of preparatory suppression on a single-trial basis: the stronger the suppression, the faster the initiation of the ensuing movement (Hannah et al. 2018). Importantly, these hypotheses could be both valid 
91 as they focus on different levels of control, which are both known to shape motor activity: while

92 the choice hypothesis suggests that suppression originates from processes that help select accurate

93 actions (i.e., therefore reducing the error rate), the motor hypothesis entails that preparatory

94 suppression is also generated by processes speeding up action initiation (i.e., therefore reducing

95 RTs).

Here, we investigated the impact of motor training on preparatory suppression, while

97 subjects practiced an instructed-delay RT task. The choice aspects were clear-cut, as evident from

98 the low error rates, even before training. Hence, in such task, the selection requirements are so low

99 that there is no room for improvement; subjects can only become more skilled at the motor level,

100 by initiating their action faster. Based on this, we predicted that RTs would decrease over the course

101 of practice but that error rates would remain marginal. In addition, we expected resting CSE to

102 increase with training, in accordance with previous work (Butefisch et al. 2000; Christiansen et al.

103 2018; Duque et al. 2008; Galea and Celnik 2009; Pascual-Leone et al. 1995). Based on the motor

104 hypothesis (i.e., that preparatory suppression fastens RTs), we expected that training would deepen

105 the drop in excitability during action preparation with respect to rest, reflecting an increased

106 preparatory suppression. Hence, we predicted that preparatory activity would not follow the training-related rise in resting CSE. 


\section{Materials and Methods}

\subsection{Participants}

Fifteen right-handed healthy subjects participated in the present study ( $\mathrm{n}=15 ; 10$ women; 22.4 \pm 1.63 years old). Handedness was assessed via Edinburgh Handedness inventory (Oldfield 1971). Participants filled out a TMS safety questionnaire to look for any contra-indication and gave written informed consent in accordance with the Ethics Committee of the Universite Catholique de Louvain and the principles of the Declaration of Helsinki. We had to exclude one subject because we encountered a technical problem during the experiment; hence, analyses were run on the fourteen remaining subjects. Part of the data reported here has been exploited in a separate study (Vassiliadis et al. 2018). All of the data are expressed as mean \pm SE.

\subsection{Task}

Subjects were sited in front of a computer screen with the hands on response devices (Fig.1A, (Quoilin et al., 2016, 2018, 2019; Grandjean et al., 2019). They performed an instructeddelay RT task, which required them to choose between abduction movements of the left or right index finger according to the position of a preparatory cue (i.e., a left- or right-sided ball separated from a goal by a gap). Participants had to prepare their movement once the ball appeared but to withhold responding until the onset of a "Go" signal (i.e., a bridge). When the bridge appeared on the screen, subjects had to respond as fast as possible, allowing the ball to roll on the bridge and to reach the goal. To reduce anticipation of the "Go" signal, the bridge did not appear in some of the trials (5\%). Trials always ended with a feedback score reflecting performance (see Fig.1B).

\subsection{TMS Protocol}

Monophasic pulses were delivered through one or two figure-of-eight shaped coils, each connected either to a Magstim 200² magnetic stimulator (Magstim, Whitland, Dyfed, UK) or a Magstim Bistim ${ }^{2}$ magnetic stimulator. The TMS machine used to stimulate each hemisphere was counterbalanced between subjects. Pulses could be triggered in one (i.e., single-coil TMS) or in the two coils (i.e., double-coil TMS, Fig.1C) because the dataset was initially acquired for a separate study to establish the reliability of double-coil TMS to probe CSE bilaterally (Grandjean et al. 
149

C.

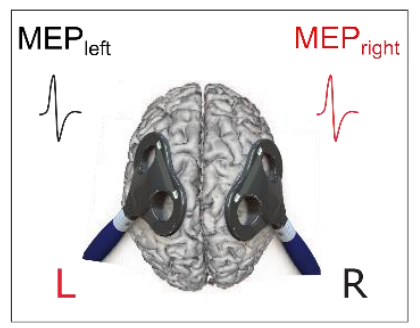

B.

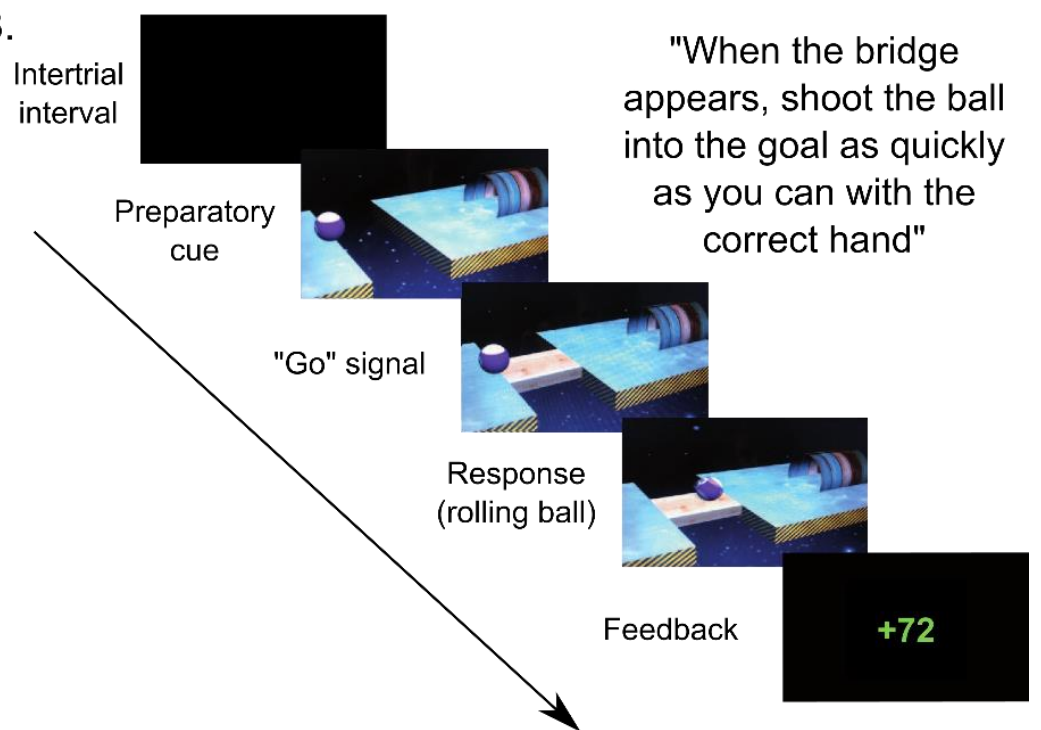

Figure 1. A, The response device. Index finger responses were recorded using a home-made device composed of two pairs of metal edges fixed on a wooden platform and positioned under the left (graphic representation) and right (photographic representation) hands. B, "Rolling Ball" task. Subjects were asked to choose between responding with the left or right index finger according to the position of a ball (Preparatory cue) appearing on the left or right part of the screen (left in the current example). They had to wait until the onset of a bridge (Go signal) to release their response as quickly as possible. The ball then rolled on the bridge (when the subjects answered correctly) to reach a goal located on the other side of the gap. A feedback reflecting how fast and accurate the subjects were concluded each trial. On correct trials, scores ranged from 1 to 100 points and were displayed in green. Participants were informed that the score was inversely proportional to the RT: 
the faster the response, the higher the score. In order to homogenize the score across subjects, scores on correct trials were individualized according to RTs measured during a familiarization session just before the main experiment (Vassiliadis et al., 2018; Grandjean et al., 2019). Incorrect responses were penalized with negative scores displayed in red. They involved responses occurring too early (RT $<100 \mathrm{~ms})$, referred to as "anticipation errors" (-75 points), responses occurring too late $(\mathrm{RT}>500 \mathrm{~ms})$, referred to as "time-out errors" (-50 points), responses provided with the incorrect hand (-20 points), referred to as "choice errors" and responses provided on catch trials (12 points), referred as "catch errors". When subjects succeeded not to respond on a catch trial, they were rewarded by +12 points. The total score was displayed at the end of each block. C, TMS protocol. Two figure-eight-shaped coils were placed over the subject's M1, eliciting MEPs in the left and/or right FDI. In double-coil trials, a 1-ms interval separated the onset of the two pulses, eliciting MEPs in both hands at a near simultaneous time (Algoet et al. 2018; Grandjean et al. 2018; Quoilin et al. 2019; Vassiliadis et al. 2018). This interval was used to avoid direct electromagnetic interference between the two coils (Cincotta et al. 2005), while preventing transcallosal interactions that would occur between motor areas with longer delays (Ferbert et al. 1992; Hanajima et al. 2001). Notably, in double-coil trials, half of the trials involved a pulse over left M1 first whereas the other half involved a pulse over right M1 first (1ms delay). These data were assembled because the a prior analysis reported elsewhere showed that the order of stimulation does not influence the double-coil MEP amplitudes, which were identical to single-coil MEPs (Vassiliadis et al. 2018).

\subsection{Experimental procedure}

The experiment started with two familiarization blocks. The first block allowed subjects to become acquainted with the task. The second block involved TMS and served to compute the median RT for each subject. The latter was used to individualize the feedback scores on correct trials according to the initial performance (see Fig.1B).

Then, subjects performed 400 trials of the task, divided in 10 blocks. Each block involved an equal combination of single- and double-coil stimulations, occurring in a random order (i.e., subjects could not anticipate the type of stimulation they would face). Given that both techniques produce equivalent MEPs (Grandjean et al. 2018; Vassiliadis et al. 2018), these data were considered regardless of the protocol used to elicit them. 

the blocks $\left(\mathrm{TMS}_{\text {baseline-out }}\right)$, providing MEPs reflecting baseline CSE at complete rest. $\mathrm{TMS}_{\text {baseline- }}$ out pulses occurred every other block, starting before block 1 and ending after block 8 ( 5 time points; 30 MEPs per time point; Fig.2A). Second, TMS occurred during the intertrial interval, $300 \mathrm{~ms}$ before the beginning of the trial (Fig.2B). MEPs recorded at this time (12 per block) provided another baseline measure of CSE, with subjects at rest but engaged in the task (TMS baseline-in Labruna et al., 2011). Finally, TMS occurred at 900 or $950 \mathrm{~ms}$ after the onset of the preparatory cue $\left(\mathrm{TMS}_{\text {preparation}}\right)$. Since no difference was found between MEPs recorded at these two timings in our previous analysis (Vassiliadis et al. 2018), these data were pooled together (48 MEPs per block). Half of these MEPs fell in left response trials, while the other half occurred in right response trials. Hence, MEPs could either fall in a hand that was selected for the forthcoming response $\left(\mathrm{MEP}_{\text {selected}} ;\right.$ e.g., left MEPs preceding a left index finger response) or in a hand that was non-

$$
\text { A. }
$$

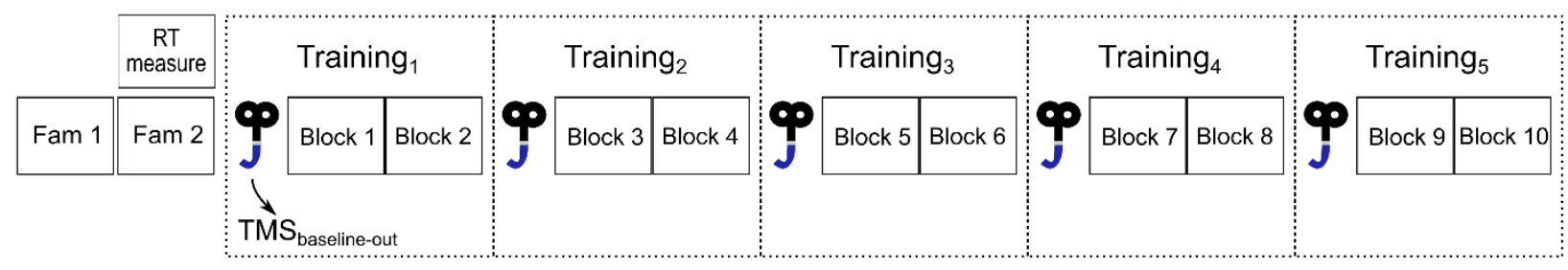

B.

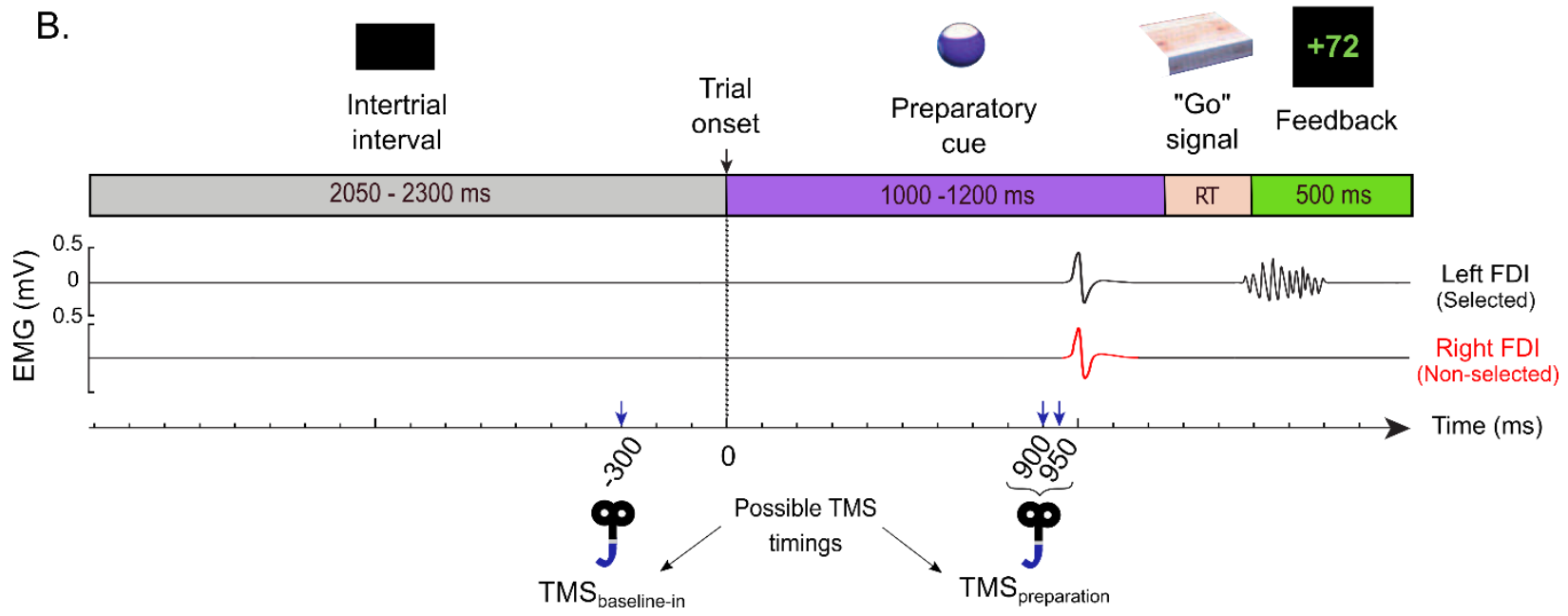

Figure 2. A, Time-course of the experiment. After two familiarization blocks (Fam1: 20 trials without TMS and Fam 2: 40 trials with TMS), subjects executed ten blocks of forty trials during 
which MEPs were elicited at $\mathrm{TMS}_{\text {baseline-in }}$ or $\mathrm{TMS}_{\text {preparation }}$ (see 2A). The effect of training was assessed by comparing five sets of data (Training 1 to Training 5 ), each involving MEPs pooled over two consecutive blocks. MEPs were also elicited outside the blocks (TMS baseline-out $)$ at five points in time, before block 1 and after blocks 2, 4, 6 and 8, categorized as Training ${ }_{1}$ to Training, similar to the MEPs elicited during the blocks. We obtained $15 \mathrm{TMS}_{\text {baseline-out }}$ MEPs per hand for each

212 Training in resting CSE outside the context of the task. B, Time course of a trial. Trials were separated by a blank screen (intertrial interval; 2050 to $2300 \mathrm{~ms}$ ) and always started with a preparatory cue appearing for a variable delay period (1000 to $1200 \mathrm{~ms}$ ). Then, a Go signal was presented and remained on the screen until a response was detected, hence for the duration of the reaction time (RT). The feedback was presented at the end of each trial for $500 \mathrm{~ms}$ and depended on the RT on correct trials. Importantly, the variable delays in the task were sampled from uniform distributions to induce temporal uncertainty and therefore reduce anticipation that could emerge with the repetition of trials. TMS pulses occurred either during the intertrial interval $(300 \mathrm{~ms}$ before the

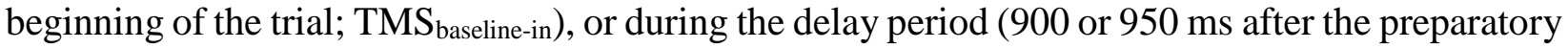

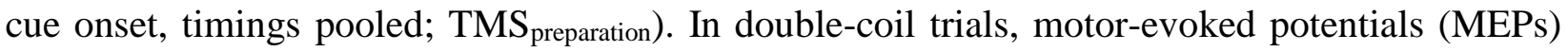
were elicited in the first dorsal interosseous (FDI) of both hands at a near simultaneous time (1 ms delay); in single-coil trials, MEPs were elicited in the left or right hand. The figure displays a left hand trial with double-coil TMS at TMS preparation.

\subsection{Data processing and statistical analyses}

The purpose of the study was twofold: (1) to characterize changes in CSE at rest and during action preparation occurring along with training in a basic instructed-delay RT task, (2) to assess whether modulations in CSE were correlated to training-related improvements in RTs. To do so, the behavioral and MEP data were evaluated according to the block within which they were elicited and data from two consecutive blocks were pooled together. Given the 10 blocks, we obtained five data sets reflecting five training stages (Training $\mathrm{STAGE}_{\mathrm{S}}$ Training ${ }_{1}$ to Training 5 ; Fig.2A).

Statistical analyses were carried out with Matlab 2018a (the Mathworks, Natick, Massachusetts, USA) and Statistica 10 (StatSoft Inc., Tulsa, Oklahoma, USA). All data were systematically tested for the sphericity assumption using Maunchley's tests. The Greenhouse- 
Geisser (GG) correction was used for sphericity when necessary. Post-hocs comparisons were always conducted using the Fisher's LSD procedure. The significance level was set at $\mathrm{p} \leq 0.05$.

\subsubsection{RTs and errors}

Left and right hand RTs were computed as the difference between the onset of the Go signal and movement onset (when the finger quitted the outer metal edge of the device). Trials where subjects made an error were removed from the data set for the RT analysis. An average of 35 left and 34 right response trials remained for each subject at each TrainingSTAGE. We computed the mean RT for left and right responses separately and then averaged these data together. Besides, we also assessed response accuracy over training, by computing, for each TrainingsTAGE, the amount of anticipation, time-out and catch errors as well as the total error rate. For each of these variables, we expressed the number of incorrect trials in percentage of the total amount of trials, regardless of the responding hand. Choice errors were not analysed because they were rare (4 choice errors across all subjects). For the statistical analysis of RTs and errors (i.e., anticipation, time-out, catch and global errors), we used one-way analyses of variance for repeated measures (ANOVARM) with the factor Training STAGE $_{\text {(Training }}$ to Training $_{5}$ ).

\subsubsection{MEP amplitudes}

MEPs were obtained by recording electromyography (EMG) bilaterally from surface electrodes (Neuroline, Medicotest, Oelstykke, Denmark) placed over the FDI. The signals were amplified (x1000), bandpass filtered (10-500Hz; NeuroloLog; Digitimer), digitalized at $2000 \mathrm{~Hz}$ and collected with Signal (Signal 3.0, Cambridge, UK) for offline analysis. Trials with background EMG activity preceding the pulse exceeding 3 SDs above the mean were discarded $(1.68 \pm 0.30 \%$ removal; Vassiliadis et al., 2018; Grandjean et al., 2018, 2019). This was done to prevent contamination of the MEP measurements by significant fluctuations in background EMG.

To assess training-related changes in resting CSE based on MEPs elicited at TMS and $\mathrm{TMS}_{\text {baseline-in, we averaged separately left and right hand MEPs for each Training }}$ STAGE before computing the mean of these averages. These data were analysed using a two-way ANOVARM with $\mathrm{TMS}_{\text {TIMING }}\left(\mathrm{TMS}_{\text {baseline-out }}\right.$ or TMS baseline-in), and Training $_{\text {STAGE }}$ (Training 1 to Training 5 ) as withinsubject factors. To assess training-related changes in preparatory suppression based on MEPs at 


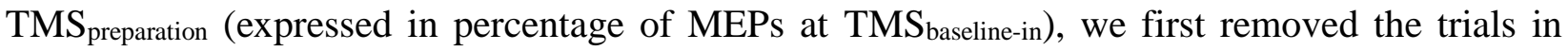
which subjects made a mistake (10.78 $\pm 1.81 \%$ removal) and then grouped left and right hand MEPs according to whether they corresponded to a $\mathrm{MEP}_{\text {selected }}$ or $\mathrm{MEP}_{\text {non-selected. Within these categories, }}$ we averaged the separate means of left and right hand MEPs for each Trainingstage. To analyse these data, we first focused on percentage MEPs at Training 1 , assessing with t-tests (against a constant value of $100 \%$ ) the significance of preparatory suppression at the beginning of training. Then, we analyzed all training stages using a two-way ANOVARM with the factors MEPSELECTION ( $\mathrm{MEP}_{\text {selected }}$ or $\mathrm{MEP}_{\text {non-selected}}$ ) and Training $\mathrm{STAGE}_{\text {(Training }}$, to Training 5 ). This ANOVA was also run on absolute MEP amplitudes (in $\mathrm{mV}$ ).

\subsubsection{Relationship between training-related changes in RTs and CSE}

As described in the Result section, training influenced RTs and CSE. We studied the relationship between changes at these two levels, with CSE considered separately at rest and during action preparation. We computed ratios reflecting training-related changes. Based on the RT data, we realized that the subjects' behavior improved substantially during the first practice stage

282 (Training 1 to Training 3 ) but then, RTs remained quite stable (from Training 3 to Training 5 ; Result section). For this reason, we considered ratios for these two phases of training separately, providing us with an indication of early (Training ${\text { ratio-early: } \text { Training }_{3} / \text { Training }_{1} \text { ) and late (Training }}_{\text {ratio-late: }}$

285 Training 5 /Training 3 ) training-related changes in RTs and CSE. For the latter, we computed separate ratios for MEPs at $\mathrm{TMS}_{\text {baseline-out, }} \mathrm{TMS}_{\text {baseline-in }}$ and $\mathrm{TMS}_{\text {preparation }}$ (expressed in percentage of MEPs

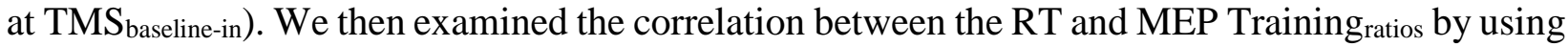
least squares linear regressions.

Finally, we compared the strength of the RT relationship to training-related changes in MEP amplitudes at $\mathrm{TMS}_{\text {baseline-in }}$ (reflecting resting CSE) and changes in percentage MEPs at $\mathrm{TMS}_{\text {preparation }}$ (reflecting preparatory suppression of CSE). To do so, in order to obtain a robust calculated a median $\mathrm{R}$ for each correlation (Efron 1979). These R-values were then compared to each other using Pearson and Fillon's z test (Pearson and Filon 1898). 


\subsubsection{Single-trial relationship between RTs and preparatory suppression}

The correlation analyses revealed a relationship between RTs and preparatory suppression: the subjects who showed the greatest training-related reduction in RTs were also those who displayed the strongest deepening in preparatory suppression (see Result section). To better understand the dependency of RTs to the strength of preparatory suppression, we investigated whether this relationship was evident on a single-trial basis, as suggested previously (Hannah et al. 2018). We selected the MEPs elicited at $\mathrm{TMS}_{\text {preparation }}$ and again, expressed them as a percentage of $\mathrm{TMS}_{\text {baseline-in. }}$ We only used the double-coil trials, to consider a homogeneous set of data, with preparatory MEPs falling in both hands systematically. For each trial, we extracted the RT, as well as the MEPs recorded at $\mathrm{TMS}_{\text {preparation }}$ in both selected $\left(\mathrm{MEP}_{\text {selected }}\right)$ and non-selected $\left(\mathrm{MEP}_{\text {non- }}\right.$ selected) hands. Hence, for each trial, we obtained one RT measure linked to two different MEPs.

To examine the relationship between RTs and preparatory suppression, we pooled the trials from all 10 blocks together and sorted them according to the amplitude of MEPs within each trial. Given that there were two MEPs in each trial, we repeated this procedure twice, providing us with two different orderings of the trials according to the $\mathrm{MEP}_{\text {selected }}$ or $\mathrm{MEP}_{\text {non-selected. Within each }}$ arrangement, trials were grouped into 6 consecutive percentile bins $\left(\mathrm{MEP}_{\mathrm{BIN}}: \mathrm{MEP}_{\mathrm{BIN}-1}=0\right.$ to $16.7 \%, \mathrm{MEP}_{\mathrm{BIN}-2}=16.7$ to $33.3 \% \ldots \mathrm{MEP}_{\mathrm{BIN}-6}=83.3$ to $100 \%$ of the data). $\mathrm{MEP}_{\mathrm{BIN}-1}$ contained the trials with the stronger preparatory suppression whereas the MEP $\mathrm{BIN}_{-6}$ included the trials with the weaker preparatory suppression. We then computed the mean RT of trials within each MEP $\mathrm{BIN}_{\mathrm{N}}$ (23 trials per condition on average and never less than 19 trials), and then averaged the corresponding RTs. Hence, we obtained six average RT values (i.e., one for each MEP $\mathrm{BIN}$ ) for each of the trial arrangements based on the two MEP types. These two sets of RT data were analysed using two separate ANOVARM with the factor $\mathrm{MEP}_{\mathrm{BIN}}\left(\mathrm{MEP}_{\mathrm{BIN}-1}\right.$ to $\left.\mathrm{MEP}_{\mathrm{BIN}-6}\right)$. 


\section{Results}

\subsection{RTs and errors}

Fig.3A shows the evolution of RTs with training. The ANOVARM revealed a significant influence of Training $\mathrm{STAGE}$ on $\mathrm{RT}\left(\mathrm{F}_{(4,52)}=4.31, \mathrm{p}=0.0043\right)$. Post-hoc tests showed that RTs measured from Training ${ }_{3}$ to Training ${ }_{5}$ were shorter than at Training ${ }_{1}$ (all $\mathrm{p}<0.004$ ). In contrast, the total error rate remained stable over the blocks $\left(\mathrm{F}_{(4,52)}=0.82, \mathrm{p}=0.52\right.$, Fig.3B $)$. We did not observe any modification of the percentage of anticipation $\left(\mathrm{F}_{(4,52)}=1.12, \mathrm{p}=0.36\right)$, time-out (GG-corrected respond more quickly while maintaining the same accuracy level.

329

A. Reaction times

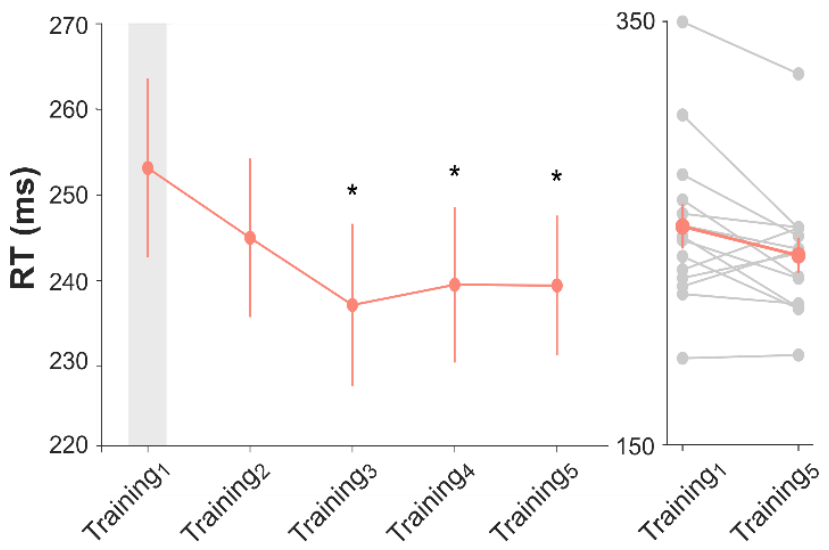

TrainingstAGE
B. Total error rate
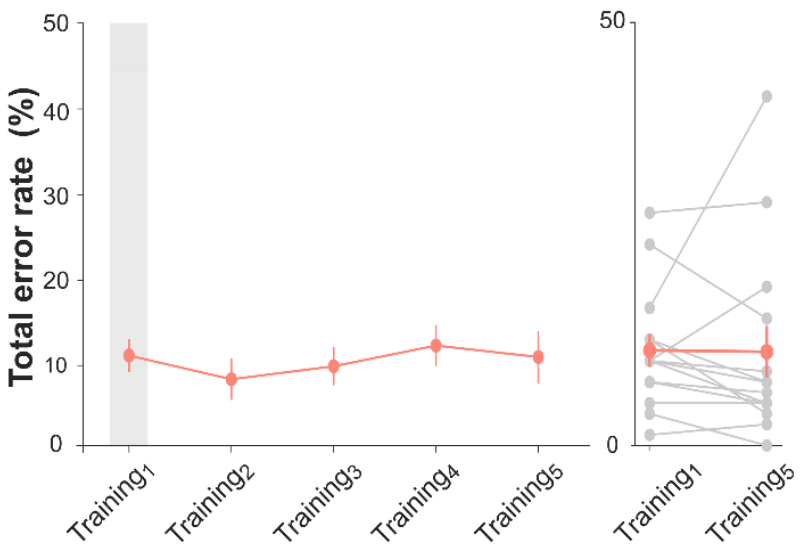

TrainingstAGE

Figure 3. Evolution of reaction times (RTs) and total error rate throughout training. The given Training ${ }_{S T A G E}$ and Training $1(\mathrm{p}<0.05)$. Individual data for Training Ind Training $_{5}$.

\subsection{MEP amplitude}

First, we evaluated the effect of training on MEPs acquired at rest. As evident on Fig.4, MEPs were larger when assessed in the context of the task (TMS $\left.S_{\text {baseline-in: }} 1.79 \pm 0.17 \mathrm{mV}\right)$ compared to when subjects were fully at rest $\left(\mathrm{TMS}_{\text {baseline-out: }} 1.34 \pm 0.17 \mathrm{mV}\right)$, as supported by the significant factor $\operatorname{TMS}_{\text {TIMING }}\left(\mathrm{F}_{(1,13)}=28.43, \mathrm{p}<0.001\right)$ and consistent with previous studies (Derosière et al. 
2015; Labruna et al. 2011). The ANOVA RM $_{\text {also revealed an effect of Training }}$ STAGE on baseline $\operatorname{MEPs}\left(\mathrm{F}_{(4,52)}=6.34, \mathrm{p}<0.001\right)$. MEPs recorded at Training 2 to Training 5 were larger than at

343 Training 1 (all $\mathrm{p}<0.03$ ). This training effect on MEPs occurred independently of the TMS TIMING: (Training $_{\text {STAGEXTMS }}$ TIMING $\left.: \mathrm{F}_{(4,52)}=0.18, \mathrm{p}=0.95\right)$.

346

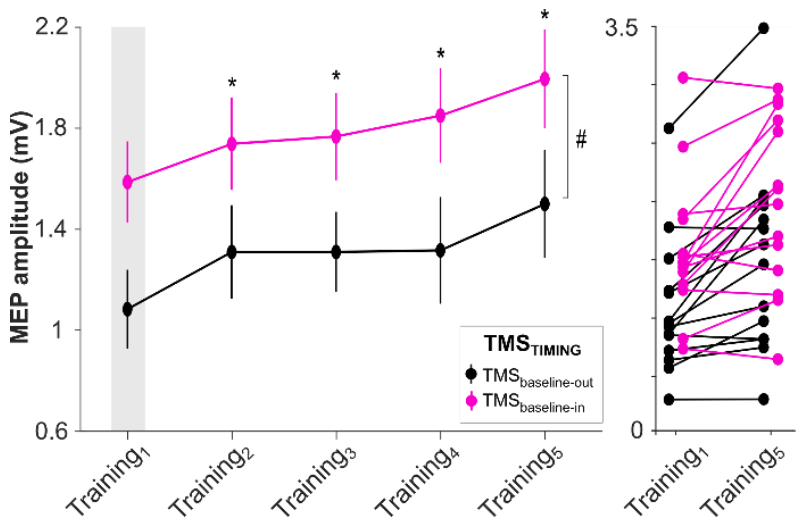

Training

Figure 4. Evolution of baseline MEPs throughout training. MEP amplitudes (in $\mathrm{mV}$ ) elicited at

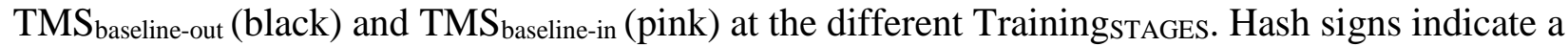

TMS $_{\text {TIMING }}$ effect. Stars denote a significant difference between a given Trainingstage and

Training $_{1}(\mathrm{p}<0.05)$. Individual data for Training and Training $_{5}$ are also displayed.

Second, we analyzed the effect of training on preparatory suppression by considering MEPs

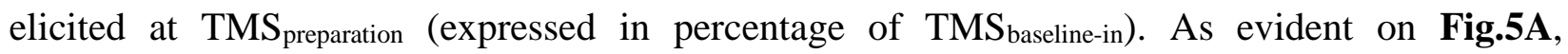
percentage FDI MEPs were initially suppressed at Training ${ }_{1}$ (MEPs smaller than 100\%), consistent with the presence of preparatory suppression in the prime-mover, whether selected for the forthcoming response $\left(\mathrm{MEP}_{\text {selected: }} 73.98 \pm 4.00 \% ; \mathrm{t}_{(13)}=-6.50, \mathrm{p}<0.0001\right)$ or not $\left(\mathrm{MEP}_{\text {non-selected: }}\right.$ $\left.76.26 \pm 4.36 \% ; \mathrm{t}_{(13)}=-5.44, \mathrm{p}<0.001\right)$. Interestingly, preparatory suppression became more prominent with training: the ANOVARM revealed a significant decrease in percentage MEP amplitudes over the Training STAGES $_{(}\left(\mathrm{F}_{(4,52)}=2.79, \mathrm{p}=0.036\right)$. This change was marginal at Training 4 (i.e., Training ${ }_{4}: \mathrm{p}=0.058$ when compared to Training ${ }_{1}$ ) and became significant at Training $(\mathrm{p}=0.006)$. It concerned MEPs obtained from the selected and non-selected hands 
related changes of preparatory activity, we ran another set of ANOVARM on absolute MEP amplitudes (rather than percentages) at $\mathrm{TMS}_{\text {preparation }}$ (Fig.5B). These MEPs did not show any fluctuation over the Trainingstages $\left(\mathrm{F}_{(4,52)}=1.30, \mathrm{p}=0.28\right)$. Moreover, we did not find any

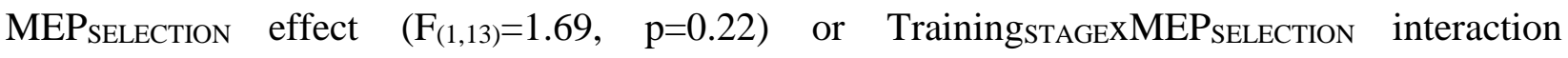
$\left(\mathrm{F}_{(4,52)}=0.85, \mathrm{p}=0.50\right)$.

In conclusion, our results indicate that training did not produce even modulatory changes in motor activity at rest and during action preparation: while resting CSE increased, preparatory suppression) with respect to the rising baseline excitability state. These changes in CSE occurred in parallel with an acceleration of RTs.

A.

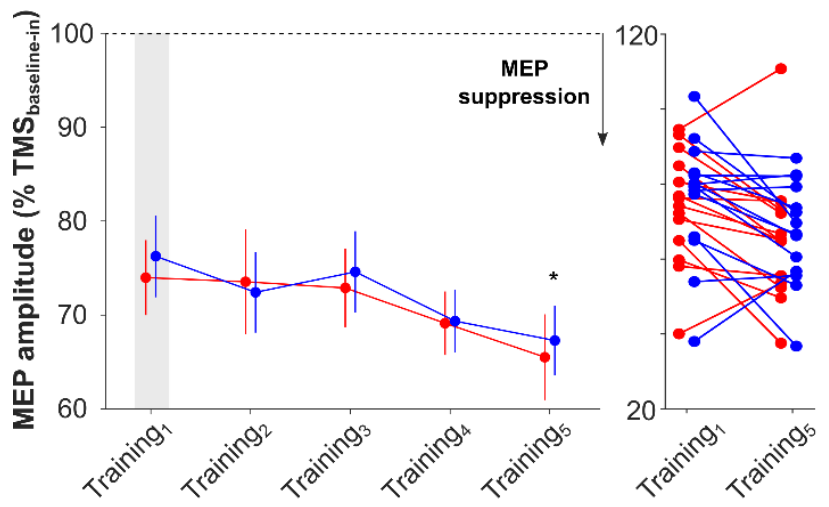

375

376

377

378

379

380
B.

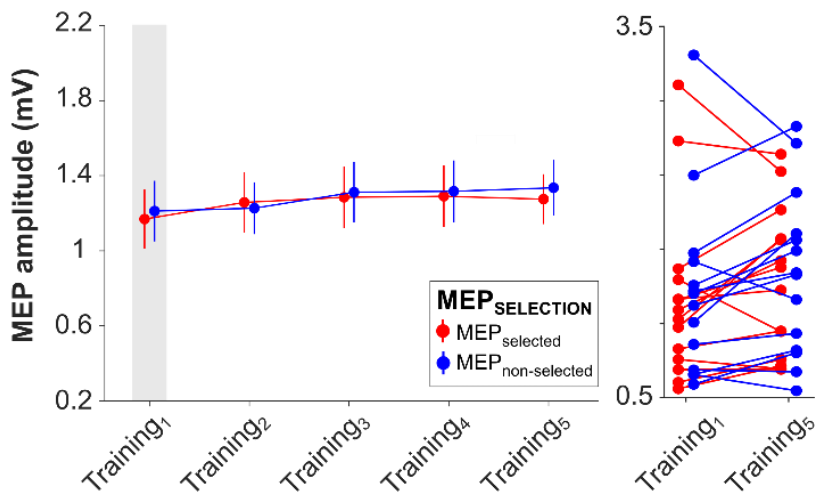

TrainingsTAGE

Figure 5. Evolution of preparatory MEPs throughout training. Normalized MEP amplitudes recorded at $\mathrm{TMS}_{\text {preparation }}$ (in percentage of MEPs elicited at $\mathrm{TMS}_{\text {baseline-in) }}$ muscles at the different Training ${ }_{\text {Stages }}$ (A). Absolute MEP data (in $\mathrm{mV}$ ) are also represented muscles (B). The star denotes a significant difference between a Training ${ }_{5}$ and Training ${ }_{1}(\mathrm{p}<0.05)$. Note that the change in preparatory suppression was close to significance at Training 4 (i.e., $\mathrm{p}=0.058$ when compared to Training $_{1}$ ). Individual data for Training ${ }_{1}$ and Training ${ }_{5}$ are also displayed.

Because RTs became shorter over the blocks, one may argue that MEPs at $\mathrm{TMS}_{\text {preparation }}$ were not recorded in a comparable preparatory state throughout training; that is, the delay between TMS and movement onset (DelayтмS-то-моve) may have decreased over the blocks. Importantly, we shuffled the delay between the pulse and the Go signal in the present study (see Methods), in 
order to prevent changes in RT to convert into equivalent changes in the Delaytms-то-моve. than Training ${ }_{1}\left(419.99 \pm 9.99 \mathrm{~ms}, \mathrm{t}_{(13)}=-3.10, \mathrm{p}=0.008\right)$, we performed an additional analysis to control for a potential bias of the Delayтмs-то-моve. We conducted a response-locked analysis whereby we classified MEP data at TMS preparation (regardless of the TrainingSTAGE) according to the DelayтмS-то-моve in 5 consecutive bins of trials $\left(\right.$ DelayвIN $=$ Delay $_{\mathrm{BIN}-1}=0$ to $20 \%$, Delay BIN $-2=20$ to $40 \%, \ldots$, Delaybin-5 $=80$ to $100 \%$ of the Delaytms-To-move data). An ANOVARm ran on these data did not reveal any effect of Delaybin $\left(\mathrm{F}_{(4,52)}=1.45 ; \mathrm{p}=0.23\right)$, nor was there any significant MEP $_{\text {SELECTIONXDelay }}$ in interaction $\left(\mathrm{F}_{(4,52)}=0.40 ; \mathrm{p}=0.81\right.$; Fig.6). These results indicate that MEPs elicited preceding a Go signal remain quite unaffected by the delay separating the $\mathrm{TMS}_{\text {preparation }}$ pulse and movement onset.

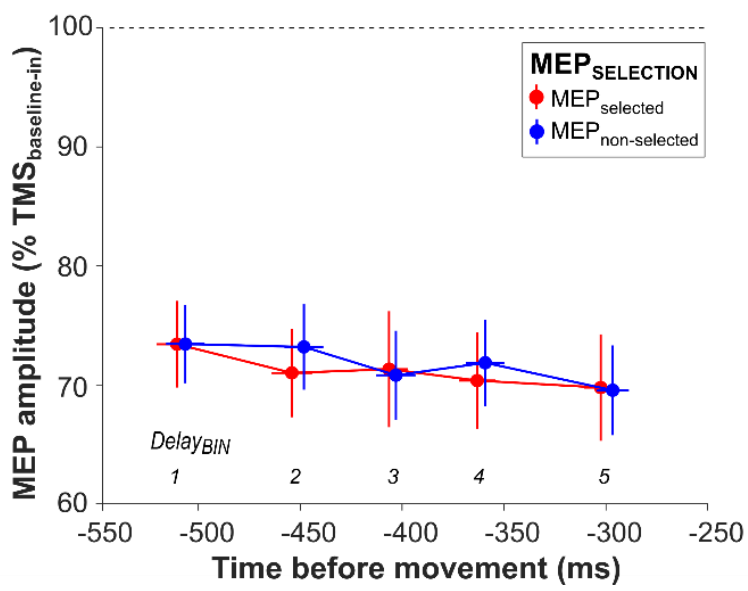

Figure 6. Preparatory suppression according to time before movement onset. MEP amplitudes

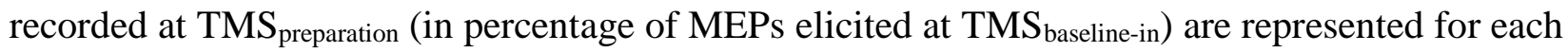
Delaybin in a selected (red) or non-selected (blue) muscle.

\subsection{Relationship between training-related changes in RTs and CSE}

Given that training influenced RTs and CSE, we studied the relationship between changes at these two levels, with CSE considered separately at rest and during action preparation. To assess the relationship between RTs and resting CSE, we ran correlations between training-related changes in RTs and changes in MEPs at $\mathrm{TMS}_{\text {baseline-in }}$ and $\mathrm{TMS}_{\text {baseline-out. These analyses did not }}$ reveal any link between variations in resting measures of CSE and changes observed in RTs, neither 
at Training ratio-early $_{(\text {Fig.7A, }} \mathrm{R}=-0.27, \mathrm{p}=0.36$ and $\mathrm{R}=0.079, \mathrm{p}=0.79$ for $\mathrm{TMS}_{\text {baseline-in }}$ and $\mathrm{TMS}_{\text {baseline- }}$ out, respectively) nor at Training ratio-late $(\mathrm{R}=-0.28, \mathrm{p}=0.33$ and $\mathrm{R}=-0.16, \mathrm{p}=0.59)$.

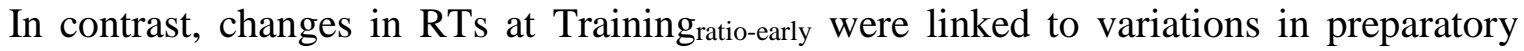
suppression observed in the selected (Fig.7B; R=0.55, p=0.043) and non-selected FDI (Fig.7C; $\mathrm{R}=0.74, \mathrm{p}=0.0027$ ): subjects showing a greater training-related strengthening of preparatory suppression also showed larger improvements in RTs. This correlation was not significant at Training ${ }_{\text {ratio-late, }}$ neither for the selected $(\mathrm{R}=0.12, \mathrm{p}=0.67)$ nor for the non-selected effectors $(\mathrm{R}=0.48, \mathrm{p}=0.084)$. Our results suggest that $\mathrm{RT}$ improvements were related to early changes in preparatory suppression.

This conclusion is further supported by an additional analysis showing that the strength of

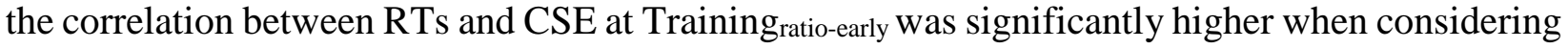

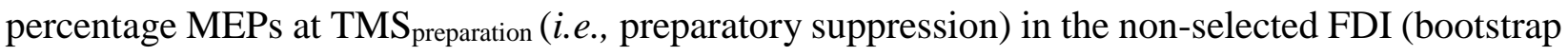
estimate of absolute $\mathrm{R}=0.76)$, than when MEPs were considered at $\mathrm{TMS}_{\text {baseline-in }}(\mathrm{R}=0.29 ; \mathrm{z}=1.75$; $\mathrm{p}=0.040$, Fig.7D). This difference was not significant when taking preparatory suppression in the selected FDI $(\mathrm{R}=0.56$; $\mathrm{z}$-score $=0.85, \mathrm{p}=0.20)$. Hence, training-related changes in preparatory suppression of the non-selected effector turned out to be the best predictor of RT improvements.

A.

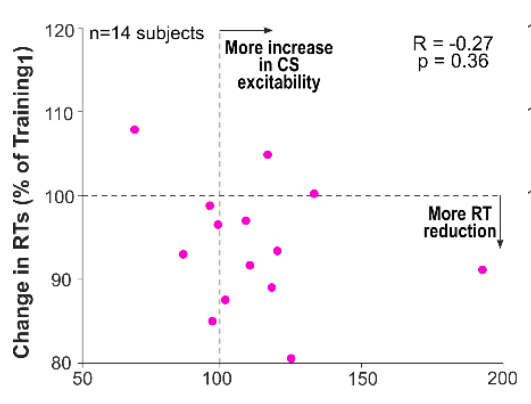

Change in resting CS excitability (\% of Training1)
B.

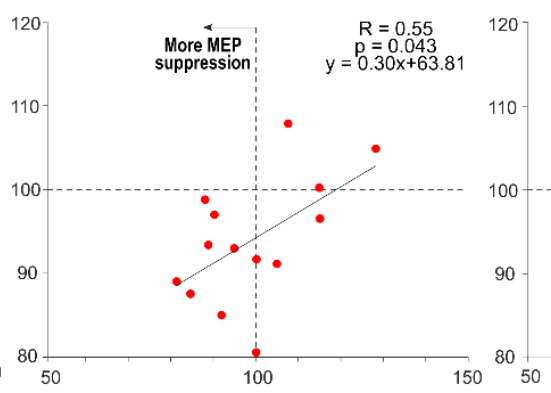

Change in preparatory suppression $(\%$ of Training 1$)$
C.

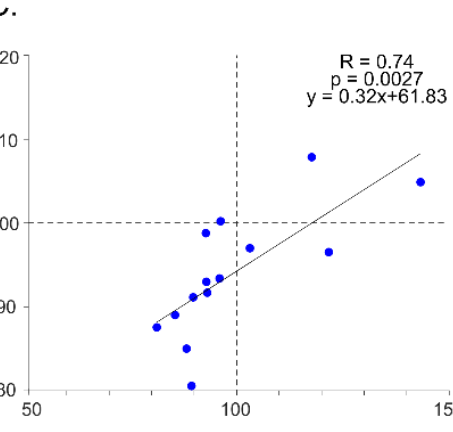

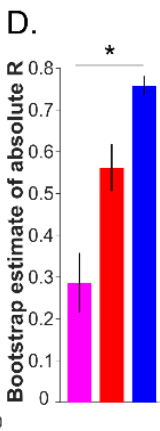

Figure 7. Correlation between early training-related changes in RTs and CSE. Changes in

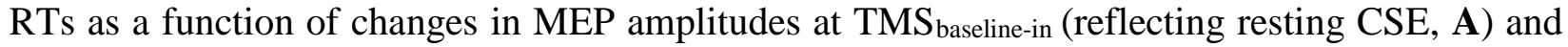
changes in percentage MEPs at $\mathrm{TMS}_{\text {preparation }}$ (reflecting preparatory suppression of CSE) in the

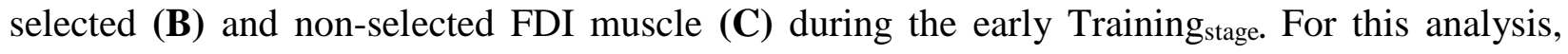
changes in RTs and MEPs were assessed by computing percentage ratios between the values obtained at Training $_{3}$ and Training 1 . (D) Bootstrap estimates of absolute $\mathrm{R}$ values are also displayed 
436

( \pm standard deviation of the samples) for each condition. These $\mathrm{R}$ values were compared by means of a Pearson and Fillon's $\mathrm{z}$ test. One tail p-values were used given our a priori hypothesis concerning the directionality of the effect $(\mathrm{p}<0.05)$.

\subsection{Single-trial relationship between RTs and preparatory suppression}

Finally, we asked whether the dependency of RTs to preparatory suppression is also evident on a single-trial basis. This was the case for MEPs recorded from the non-selected hand: the greater the preparatory suppression in that hand, the shorter the following RT (Fig.8, right panel), as supported by the ANOVARM revealing an effect of the factor MEP BIN $_{\text {on }}$ RTs $\left(\mathrm{F}_{(5,65)}=2.57\right.$, $\mathrm{p}=0.035$ ). Post-hoc tests revealed that RTs in MEP $\mathrm{BIN}_{-1}$ and $\mathrm{MEP}_{\mathrm{BIN}-2}$ (i.e., strongest preparatory suppression) were systematically shorter than those in $\mathrm{MEP}_{\mathrm{BIN}-6}(\mathrm{p}=0.0021$ and $\mathrm{p}=0.0090)$. We did not observe any relationship between RTs and MEPs obtained in the selected hand (MEP $\mathrm{BIN}$ : GGcorrected $\mathrm{F}_{(2.22,28.88)}=0.85$, $\mathrm{p}=0.45$; Fig.8, left panel). Hence, the training-related effects and the single-trial relationship indicates that preparatory suppression in the non-selected (non-responding) hand is a predictor of the following RT. The lower this activity, the faster the response.

A. MEP $P_{\text {selected }}$

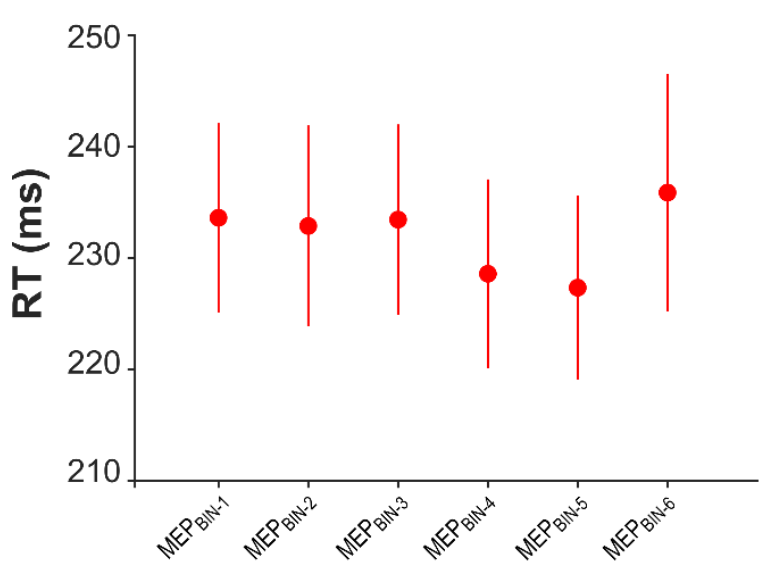

B. MEP $P_{\text {non-selected }}$

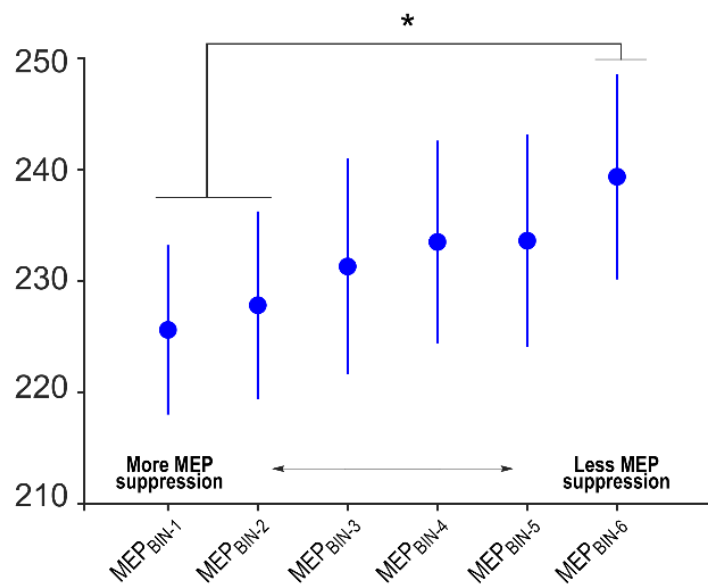

Percentile bins of preparatory suppression

Figure 8. Single-trial MEP-RT relationship. Averaged RTs as a function of the preceding preparatory suppression in a selected (left panel) or non-selected muscle (right panel). For this analysis, the MEP data were divided in $6 \mathrm{MEP}_{\mathrm{BIN}}$ of increasing amplitude and the RTs corresponding to each $\mathrm{MEP}_{\mathrm{BIN}}$ were averaged. The star denotes a significant difference between RTs at $\mathrm{MEP}_{\mathrm{BIN}-1}$ and $\mathrm{MEP}_{\mathrm{BIN}-2}$ and $\mathrm{RT}_{\mathrm{s}}$ at $\mathrm{MEP}_{\mathrm{BIN}-6}$ in the non-selected muscle $(\mathrm{p}<0.05)$. Note that 
bioRxiv preprint doi: https://doi.org/10.1101/2020.02 14.948877; this version posted June 20, 2020. The copyright holder for this preprint (which was not certified by peer review) is the author/funder, who has granted bioRxiv a license to display the preprint in perpetuity. It is made available under aCC-BY-NC-ND 4.0 International license.

455 there was also a trend for RTs at $\mathrm{MEP}_{\mathrm{BIN}-1}$ to be shorter than those in $\mathrm{MEP}_{\mathrm{BIN}-4}(\mathrm{p}=0.070)$ and $456 \quad \mathrm{MEP}_{\mathrm{BIN}-5}(\mathrm{p}=0.066)$. 


\section{Discussion}

Training accelerated RTs while errors remained low. CSE became larger at rest and preparatory suppression of CSE was stronger after training. Interestingly, subjects who showed the strongest RT improvements at the early TrainingSTAGES were also those displaying the largest initial strengthening in preparatory suppression, especially when probed in the non-selected hand. Such a relationship between RTs and preparatory suppression was also evident at a single-trial level: RTs were generally faster in trials where preparatory suppression was deeper.

Subjects responded faster with training. RTs reflect the sum of the time required for processing the imperative cue, preparing the motor command and initiating the action (Derosiere components. Previous studies have shown that RT improvements can result from both faster sensory processing (Clark et al. 2015) and more efficient motor preparation (Mawase et al. 2018). Yet, in an instructed-delay task, the time required for sensory processing and motor preparation is strongly constrained and most of the RT is assumed to reflect the time needed for action initiation (Haith et al. 2016). Hence, the RT gains reported here are likely to reflect a reduction in initiation time. Our findings thus yield an extension of former work, suggesting that, in addition to accelerating sensory processing and motor preparation, training can also boost action initiation.

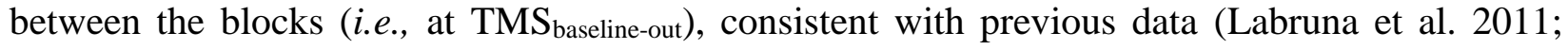
Vassiliadis et al. 2018) and with the observation that task-driven increases in attention amplifies cortical excitability (Kastner et al. 1998, 1999). As expected based on prior observations (e.g., (Butefisch et al. 2000; Christiansen et al. 2018; Duque et al. 2008; Galea and Celnik 2009; PascualLeone et al. 1995), practicing the task led to an increase in resting CSE. Interestingly, this increase was not exclusive to the task and was in fact strongly similar at $\mathrm{TMS}_{\text {baseline-in }}$ and $\mathrm{TMS}$ baseline-out, ruling out the possibility that it resulted from a change in task-related attention over practice (Derosière et al. 2015). Rather, our findings support the idea of a plastic reorganization of the motor system, measurable when engaged in the task as well as at rest.

CSE was reduced during action preparation when compared to baseline (during the task), reflecting the well-known preparatory suppression effect (Duque et al. 2017), which was evident 
in the selected and non-selected hands from the beginning of the training. Contrary to rest, the amplitude of MEPs at $\mathrm{TMS}_{\text {preparation }}$ did not increase with practice (they remained unchanged), reflecting a strengthening drop in CSE from the rising baseline state. Notably, although at the group level this reinforcement of preparatory suppression appeared late (Fig.5A), at the individual level, a majority of subjects already exhibited a strengthening of preparatory suppression at early training stages (Fig.6).

Based on these findings, one could propose that changes in resting excitability are key to RT improvements, as suggested by the inverse relationship between baseline CSE and RTs described recently (Greenhouse et al. 2017). Yet, we did not find a relationship between trainingrelated changes in baseline excitability and improvements in performance. This is in line with the idea that increased resting CSE is not crucial for immediate performance (Bologna et al. 2015), but may be involved in the long-term retention of the motor behavior (Cantarero et al. 2013). Rather, what was predictive of RT gains in the present study was the change in relative CSE, as measured during action preparation: subjects showing the strongest reinforcement of preparatory suppression at the early TrainingSTAGES were those who became fastest. These results are consistent with animal studies showing that behavioral improvements in motor learning tasks are associated with changes in relative preparatory activity (Mandelblat-Cerf et al. 2009; Paz et al. 2003; Vyas et al. 2018). Similarly, a recent study using paired-pulse TMS showed that changes in preparatory activity of M1 intra-cortical circuits are correlated to training-related behavioral gains, contrary to changes observed at rest (Dupont-Hadwen et al. 2018). More generally, our findings agree with the idea that efficient action preparation relies on dynamical shifts of neural activity from a baseline state to a preparatory state (Churchland et al. 2012). From this point of view, training may allow tuning the dynamics of preparatory activity, bringing it closer to an optimal state for action initiation (Vyas et al. 2018). In this line, strengthening of preparatory suppression would facilitate action initiation by allowing excitatory inputs targeting the selected motor representation to better stand out against a quiescent background (mostly reflected in the excitability of non-selected effector), ultimately speeding up RTs (Greenhouse et al. 2015; Hasbroucq et al. 1997; Hasegawa et al. 2017).

This interpretation was reinforced by our single-trial analysis showing that RTs depended on the foregoing amount of preparatory suppression. That is, stronger levels of suppression were related to faster initiation times in the very same trials, in agreement with previous results (Hannah et al. 2018; Hasegawa et al. 2017). Interestingly, we found such relationship when considering the 
518 non-selected prime-mover but not the selected one. This was also the case for training-related 519 effects, with preparatory suppression in the non-selected effector appearing as the best predictor of

520 RT changes, possibly because the selected effector is targeted by too many overlapping inputs to

521 supply as meaningful MEP amplitudes (Duque and Ivry 2009). Overall, our data support the view

522 that preparatory suppression facilitates rapid motor initiation. 


\section{Conclusion}

524 This study shows that a simple training paradigm can lead to improvements in action 525 initiation that are accompanied by an increase in resting CSE and a strengthening of corticospinal

526 suppression from the rising baseline state. Moreover, contrary to changes in resting CSE, such

527 strengthening of preparatory suppression was linked to RTs improvements. These findings could

528 have implications for the rehabilitation of patients suffering from impaired action initiation such as

529 in cerebellar ataxia (Battaglia et al. 2006) or Parkinson's disease (Mure et al. 2012). 


\section{Additional information}

531 Data availability:

532 The data that support the findings of this study are available at: https://osf.io/8p5wm/ (Vassiliadis

533 2020).

534

535 Conflict of interest:

536 The authors declare no conflict of interest.

537

538 Author contributions:

539 PV, GD, JG, JD: conception and design of the work; PV, JG: acquisition of data; PV: analysis of

540 data; PV, GD, JD interpretation of data; PV: drafting; PV, GD, JG, JD revising the manuscript.

541

542 Funding:

543 P.V. and J.G. were PhD students supported by the Fund for Research training in Industry and

544 Agriculture (FRIA/FNRS; FC29690 and FC09115). G.D. was a post-doctoral fellow supported by

545 the Belgian National Funds for Scientific Research (FNRS, 1B134.18). J.D. was supported by

546 grants from the Belgian FNRS (F.4512.14) and the Fondation Médicale Reine Elisabeth (FMRE). 


\section{References}

Algoet M, Duque J, Iannetti GD, Mouraux A. Temporal Profile and Limb-specificity of Phasic Pain-Evoked Changes in Motor Excitability. Neuroscience 386: 240-255, 2018.

\section{Battaglia F, Quartarone A, Ghilardi MF, Dattola R, Bagnato S, Rizzo V, Morgante L,}

Girlanda P. Unilateral cerebellar stroke disrupts movement preparation and motor imagery. Clin Neurophysiol 117: 1009-1016, 2006.

Bologna M, Rocchi L, Paparella G, Nardella A, Li P, Conte A, Kojovic M, Rothwell JC,

Berardelli A. Brain Stimulation Reversal of Practice-related Effects on Corticospinal Excitability has no Immediate Effect on Behavioral Outcome. Brain Stimul 8: 603-612, 2015.

Butefisch CM, Davis BC, Wise SP, Sawaki L, Kopylev L, Classen J, Cohen LG. Mechanisms of use-dependent plasticity in the human motor cortex. Proc Natl Acad Sci 97: 3661-3665, 2000.

Cantarero G, Lloyd A, Celnik P. Reversal of Long-Term Potentiation-Like Plasticity Processes after Motor Learning Disrupts Skill Retention. J Neurosci 33: 12862-12869, 2013.

Christiansen L, Madsen MJ, Bojsen-møller E, Thomas R, Nielsen JB. Brain Stimulation Progressive practice promotes motor learning and repeated transient increases in corticospinal excitability across multiple days. Brain Stimul 11: 346-357, 2018.

Churchland MM, Cunningham JP, Kaufman MT, Foster JD, Nuyujukian P, Ryu SI,

Shenoy K V., Shenoy K V. Neural population dynamics during reaching. Nature 487: 51-56, 2012.

\section{Cincotta M, Borgheresi A, Jung P, Balestrieri F, Giovannelli F, Zaccara G, Ziemann U.}

Physical interactions between induced electrical fields can have substantial effects on neuronal excitation during simultaneous TMS of two brain areas. Clin Neurophysiol 116: 1733-1742, 2005.

Clark K, Gregory Appelbaum L, van den Berg B, Mitroff SR, Woldorff MG. Improvement in visual search with practice: Mapping learning-related changes in neurocognitive stages of processing. J Neurosci 35: 5351-5359, 2015.

Derosiere G. A Dynamical System Framework for Theorizing Preparatory Inhibition. J Neurosci 38: 3391-3393, 2018.

Derosière G, Billot M, Ward ET, Perrey S. Adaptations of motor neural structures' activity to 
lapses in attention. Cereb Cortex 25: 66-74, 2015.

Derosiere G, Duque J. Tuning the Corticospinal System: How Distributed Brain Circuits Shape Human Actions. Neurosci 107385841989675, 2020.

Derosiere G, Thura D, Cisek P, Duque J. Motor cortex disruption delays motor processes but not deliberation about action choices. J Neurophysiol 122: 1566-1577, 2019.

Derosiere G, Vassiliadis P, Demaret S, Zénon A, Duque J. Learning stage-dependent effect of M1 disruption on value-based motor decisions. Neuroimage , 2017a. doi:10.1016/j.neuroimage.2017.08.075.

Derosiere G, Vassiliadis P, Duque J. Advanced TMS approaches to probe corticospinal excitability during action preparation. Neuroimage 213: 116746, 2020.

Derosiere G, Zénon A, Alamia A, Duque J. Primary motor cortex contributes to the implementation of implicit value-based rules during motor decisions. Neuroimage 146: 11151127, 2017b.

Dupont-Hadwen J, Bestmann S, Stagg CJ. Motor training modulates intracortical inhibitory dynamics in motor cortex during movement preparation. Brain Stimul , 2018. doi:10.1016/j.brs.2018.11.002.

Duque J, Greenhouse I, Labruna L, Ivry RB. Physiological Markers of Motor Inhibition during Human Behavior. Trends Neurosci 40: 219-236, 2017.

Duque J, Ivry RB. Role of corticospinal suppression during motor preparation. Cereb Cortex 19: 2013-2024, 2009.

Duque J, Labruna L, Cazares C, Ivry RB. Dissociating the influence of response selection and task anticipation on corticospinal suppression during response preparation. Neuropsychologia 65: 287-296, 2014.

Duque J, Lew D, Mazzocchio R, Olivier E, Richard B. Evidence for two concurrent inhibitory mechanisms during response preparation. J Neurosci 30: 3793-3802, 2010.

Duque J, Mazzocchio R, Stefan K, Hummel F, Olivier E, Cohen LG. Memory formation in the motor cortex ipsilateral to a training hand. Cereb Cortex 18: 1395-1406, 2008.

Duque J, Petitjean C, Swinnen SP. Effect of aging on motor inhibition during action preparation under sensory conflict. Front Aging Neurosci 8: 1-14, 2016. 
605

606

607

608

609

610

611

612

613

614

615

616

617

618

619

620

621

622

623

624

625

626

627

628

629

630

631

632

633

Efron B. Bootstrap Methods: Another Look at the Jackknife. Ann Stat 7: 1-26, 1979.

Ferbert A, Priori A, Rothwell JC, Day BL, Colebatch JG, Marsden CD. Interhemispheric inhibition of the human motor cortex. J Physiol 453: 525-546, 1992.

Galea JM, Celnik P. Brain Polarization Enhances the Formation and Retention of Motor Memories. J Neurophysiol 102: 294-301, 2009.

Grandjean J, Derosiere G, Vassiliadis P, Quemener L, Wilde Y de, Duque J. Towards assessing corticospinal excitability bilaterally: Validation of a double-coil TMS method. $J$ Neurosci Methods 293: 162-168, 2018.

Grandjean J, Quoilin C, Duque J. Investigating the effect of anticipating a startling acoustic stimulus on preparatory inhibition. Neurophysiol Clin 49: 137-147, 2019.

Greenhouse I, Sias a., Labruna L, Ivry RB. Nonspecific Inhibition of the Motor System during Response Preparation. J Neurosci 35: 10675-10684, 2015.

Greenhouse XI, King XM, Noah XS, Maddock XRJ, Ivry RB. Individual Differences in Resting Corticospinal Excitability Are Correlated with Reaction Time and GABA Content in Motor Cortex. J Neurosci 37: 2686-2696, 2017.

Haith AM, Pakpoor J, Krakauer JW. Independence of Movement Preparation and Movement Initiation. J Neurosci 36: 3007-3015, 2016.

Hanajima R, Ugawa Y, Machii K, Mochizuki H, Terao Y, Enomoto H, Furubayashi T, Shiio Y, Uesugi H, Kanazawa I. Interhemispheric facilitation of the hand motor area in humans. J Physiol 531: 849-859, 2001.

Hannah R, Cavanagh SE, Tremblay S, Simeoni S, Rothwell JC. Selective suppression of local interneuron circuits in human motor cortex contributes to movement preparation. J Neurosci 38: 2869-17, 2018.

Hasbroucq T, Kaneko H, Akamatsu M, Possamaï CA. Preparatory inhibition of cortico-spinal excitability: A transcranial magnetic stimulation study in man. Cogn Brain Res 5: 185-192, 1997. Hasegawa M, Majima K, Itokazu T, Maki T, Albrecht UR, Castner N, Izumo M, Sohya K, Sato TK, Kamitani Y, Sato TR. Selective Suppression of Local Circuits during Movement Preparation in the Mouse Motor Cortex. Cell Rep 18: 2676-2686, 2017.

Kastner S, Pinsk MA, De Weerd P, Desimone R, Ungerleider LG. Increased Activity in 
634

635

636

637

638

639

640

641

642

643

644

645

646

647

648

649

650

651

652

653

654

655

656

657

658

659

660

661

662

Human Visual Cortex during Directed Attention in the Absence of Visual Stimulation. Neuron 22: 751-761, 1999.

Kastner S, De Weerd P, Desimone R, Ungerleider LG. Mechanisms of Directed Attention in the Human Extrastriate Cortex as Revealed by Functional MRI. Science (80- ) 282: 108-111, 1998.

Klein PA, Petitjean C, Olivier E, Duque J. Top-down suppression of incompatible motor activations during response selection under conflict. Neuroimage 86: 138-149, 2014.

\section{Krakauer JW, Ghilardi MF, Mentis M, Barnes A, Veytsman M, Eidelberg D, Ghez C.}

Differential Cortical and Subcortical Activations in Learning Rotations and Gains for Reaching:

A PET Study. J Neurophysiol 91: 924-933, 2004.

Krakauer JW, Hadjiosif AM, Xu J, Wong AL, Haith AM. Motor Learning. 9: 613-663, 2019.

Labruna L, Fernández-Del-Olmo M, Ivry RB. Comparison of different baseline conditions in evaluating factors that influence motor cortex excitability. Brain Stimul 4: 152-155, 2011.

Makino H, Ren C, Liu H, Kim AN, Kondapaneni N, Liu X, Kuzum D, Komiyama T.

Transformation of Cortex-wide Emergent Properties during Motor Learning. Neuron 94: 880890.e8, 2017.

Mandelblat-cerf Y, Paz R, Vaadia E. Trial-to-Trial Variability of Single Cells in Motor Cortices Is Dynamically Modified during Visuomotor Adaptation. J Neurosci 29: 15053-15062, 2009.

Mawase F, Lopez D, Celnik PA, Haith AM. Movement Repetition Facilitates Response Preparation. Cell Rep 24: 801-808, 2018.

Mawase F, Uehara S, Bastian AJ, Celnik P. Motor Learning Enhances Use-Dependent Plasticity. J Neurosci 37: 2673-2685, 2017.

Mure H, Tang CC, Argyelan M, Ghilardi MF, Kaplitt MG, Dhawan V, Eidelberg D.

Improved sequence learning with subthalamic nucleus deep brain stimulation: Evidence for treatment-specific network modulation. J Neurosci 32: 2804-2813, 2012.

Oldfield RC. The assessment and analysis of handedness: The Edinburgh inventory. Neuropsychologia 9: 97-113, 1971.

Pascual-Leone A, Nguyet D, Cohen LG, Brasil-Neto JP, Cammarota A, Hallett M, Nguyen 
KT, Cohen a D, Brasil-Neto JP, Cammarota A, Hallett M, Nguyet D, Cohen LG, BrasilNeto JP, Cammarota A, Hallett M, Cohen G, Cammarota A, Pascual-Leone A, Nguyet D, Cohen LG, Brasil-Neto JP, Hallett M, Cammarota A, Hallett M, Cohen G, Cammarota A, Pascual-Leone A, Nguyet D, Cohen LG, Brasil-Neto JP, Hallett M. Modulation of muscle responses evoked by transcranial magnetic stimulation during the acquisition of new fine motor skills. [Online]. J Neurophysiol 74: 1037-1045, 1995http://www.ncbi.nlm.nih.gov/pubmed/7500130.

Paz R, Boraud T, Natan C, Bergman H, Vaadia E. Preparatory activity in motor cortex reflects learning of local visuomotor skills. 6: 882-890, 2003.

Pearson K, Filon L. VII. Mathematical contributions to the theory of evolution.- IV. On the probable errors of frequency constants and on the influence of random selection on variation and correlation. Philos Trans R Soc London 191: 229-311, 1898.

Quoilin C, Fievez F, Duque J. Preparatory inhibition: Impact of choice in reaction time tasks. Neuropsychologia 129: 212-222, 2019.

Quoilin C, Lambert J, Jacob B, Klein PA, Duque J. Comparison of motor inhibition in variants of the instructed-delay choice reaction time task. PLoS One 11: 1-16, 2016.

Quoilin C, Wilhelm E, Maurage P, Timary P De, Duque J. Deficient inhibition in alcoholdependence : let's consider the role of the motor system ! Neuropsychopharmacology 0-8, 2018.

Reis J, Swayne OB, Vandermeeren Y, Camus M, Dimyan MA, Harris-Love M, Perez MA, Ragert P, Rothwell JC, Cohen LG. Contribution of transcranial magnetic stimulation to the understanding of cortical mechanisms involved in motor control. J Physiol 586: 325-351, 2008.

Rosenkranz K, Kacar A, Rothwell JC. Differential modulation of motor cortical plasticity and excitability in early and late phases of human motor learning. J Neurosci 27: 12058-12066, 2007.

Shmuelof L, Yang J, Caffo B, Mazzoni P, Krakauer JW. The neural correlates of learned motor acuity. 971-980, 2014.

Steele CJ, Penhune VB. Specific increases within global decreases: A functional magnetic resonance imaging investigation of five days of motor sequence learning. J Neurosci 30: 83328341, 2010.

Vassiliadis P. Training_Motor_Preparation_TMS [Online]. 2020.https://osf.io/8p5wm/. 
692 Vassiliadis P, Grandjean J, Derosiere G, Wilde Y De. Using a Double-Coil TMS Protocol to 693 Assess Preparatory Inhibition Bilaterally. Front Neurosci 12: 1-14, 2018.

694 Vyas S, Even-Chen N, Stavisky SD, Ryu SI, Nuyujukian P, Shenoy K V. Neural Population 695 Dynamics Underlying Motor Learning Transfer. Neuron 97: 1177-1186.e3, 2018.

696 Vyas S, O’Shea DJ, Ryu SI, Shenoy K. Causal role of motor preparation during error-driven 697 learning. Neuron 1-11, 2020.

698 Wenger E, Kühn S, Verrel J, Mårtensson J, Bodammer NC, Lindenberger U, Lövdén M.

699 Repeated Structural Imaging Reveals Nonlinear Progression of Experience-Dependent Volume

700 Changes in Human Motor Cortex. Cereb Cortex 27: 2911-2925, 2017.

701 Wiestler T, Diedrichsen J. Skill learning strengthens cortical representations of motor 702 sequences. Elife 2013: 1-20, 2013.

703 Yokoi A, Diedrichsen J. Neural Organization of Hierarchical Motor Sequence Representations 704 in the Human Neocortex. Neuron 103: 1178-1190.e7, 2019. 